\title{
Decision support for large-scale remediation strategies by fused urban metabolism
} and life cycle assessment

Ohms, Pernille; Andersen, Camilla; Landgren, Mathilde; Birkved, Morten

Published in:

International Journal of Life Cycle Assessment

Link to article, DOI:

10.1007/s11367-018-1445-9

Publication date:

2019

Document Version

Peer reviewed version

Link back to DTU Orbit

Citation $(A P A)$ :

Ohms, P., Andersen, C., Landgren, M., \& Birkved, M. (2019). Decision support for large-scale remediation strategies by fused urban metabolism and life cycle assessment. International Journal of Life Cycle Assessment, 24(7), 1254-1268. https://doi.org/10.1007/s11367-018-1445-9

\section{General rights}

Copyright and moral rights for the publications made accessible in the public portal are retained by the authors and/or other copyright owners and it is a condition of accessing publications that users recognise and abide by the legal requirements associated with these rights.

- Users may download and print one copy of any publication from the public portal for the purpose of private study or research.

- You may not further distribute the material or use it for any profit-making activity or commercial gain

- You may freely distribute the URL identifying the publication in the public portal 
Ohms, P., Andersen, C., Landgren, M., \& Birkved, M. (2018). Decision support for large-scale remediation strategies by fused urban metabolism and life cycle assessment. International Journal of Life Cycle Assessment (In Press). P.1-15. DOI: 10.1007/s11367-018-1445-9

\title{
Decision support for large scale remediation strategies by fused Urban Metabolism and Life Cycle Assessment
}

\author{
Pernille Ohms ${ }^{1}$, Camilla Andersen ${ }^{1}$, Mathilde Landgren ${ }^{1}$ and Morten Birkved ${ }^{2}$ \\ ${ }^{1}$ Department of Civil Engineering, Technical University of Denmark, Brovej, Building 118, Kongens \\ Lyngby, Denmark \\ ${ }^{2}$ Department of Management Engineering, Technical University of Denmark, Produktionstorvet, \\ Building 424, Kongens Lyngby, Denmark \\ ORCIDs
}

Pernille Ohms: 0000-0001-5542-7720

Camilla Andersen: 0000-0001-7750-8329

Mathilde Landgren: 0000-0002-1238-1379

Morten Birkved: 0000-0001-6989-1647

\begin{abstract}
Purpose: This paper seeks to identify the most environmental friendly way of conducting a refurbishment of Broendby Strand, with focus on PCB-remediation. The actual identification is conducted by comparing four compared remediation techniques using Urban Metabolism fused with Life Cycle Assessment (UM-LCA) in combination with information relating to cost and efficiency of the compared techniques. The methodological goal of our paper is to test UM-LCA as a decision support tool and discuss application of the method in relation to large refurbishment projects.
\end{abstract}

Methods: To assess the environmental performance of PCB-remediation techniques the UM-LCA method was applied. By combining UM and LCA methodologies the total environmental impact potentials of the remediation techniques were calculated. To build an inventory for each technique we contacted and interviewed experts and studied existing literature, cases and projects in order to compile information on practical details of the techniques. To process the collected inventory data, we used the simplified product system modelling software Quantis Suite 2.0 (QS2.0). In order to validate the results from the simplified software we carried out the exact same analysis using a more complex tool OpenLCA 1.5. Based on the assessment results, we compared the remediation techniques and identified the techniques with the smallest and largest environmental impact potentials.

Results and discussion: The results obtained are presented and the technique with the smallest impact identified. A comparison between the two software tools applied is made and differences between the two are discussed in detail. Further discussed is how possible inventory errors affect the results and if any assumptions should be considered as critical for the final results. Furthermore, are the remediation efficiencies of each technique and the cost of each method considered and compared. Finally, UMLCA's ability to work as a tool for decision support is discussed and possible ways of implementing the method in sustainable decision-making is considered. 
Ohms, P., Andersen, C., Landgren, M., \& Birkved, M. (2018). Decision support for large-scale remediation strategies by fused urban metabolism and life cycle assessment. International Journal of Life Cycle Assessment (In Press). P.1-15. DOI: 10.1007/s11367-018-1445-9

Conclusions: In this study it is found that the most environmental friendly PCB-remediation technique is thermal desorption whereas the technique with the largest environmental impact potential is sand blasting, due to the environmental impacts induced in relation to disposal of the building waste. It is concluded that the UM-LCA method can be applied as a tool for decision support and if economic aspects are incorporated, the UM-LCA approach could be an essential approach for designing sustainable buildings.

Key words: UM-LCA, PCBs, remediation techniques, decision support, renovation, hazardous building materials

\section{Introduction}

In the 1950's to 1970's polychlorinated biphenyls (PCB) were used in many industries, building materials and in products such as sealants, capacitors, paint and oil (Dansk asbestforening, 2010). PCB was a useful additive because of its chemical properties including fire resistance and softening abilities. Of the PCB used worldwide, the use in sealants was the most common (Dansk asbestforening, 2010). However, through the 1970's the use of PCB was prohibited due to its inherent toxic properties, which may cause effects in the environment and affect human health (Sundhedsstyrelsen, Trafik- og Byggestyrelsen, Miljø- og Fødevareministeriet, Arbejdstilsynet, \& Udlændinge-, 2014). If materials containing PCB are disposed of incorrectly, the PCB in the waste may be discharged into the environment where it accumulates and eventually may end up in marine animals, some of which are part of a human diet (Dansk asbestforening, 2010). Hence PCB poses a challenge to human health. In addition to the behavior of PCB in the ambient environment, PCB may pollute the indoor environment where it can be absorbed in the human body and once again via an additional exposure pathway pose a threat to human health (Dansk asbestforening, 2010). Today PCB is declared among the ten most hazardous substances in the world (Sundhedsstyrelsen et al., 2014). The risks associated with PCB demands awareness on how to handle materials containing PCB, which is why The Danish Health Authorities have determined a set of PCB action values, see Table 1, defining when to act on PCB in the indoor climate (Sundhedsstyrelsen et al., 2014).

A housing estate located in the suburban area of Broendby Strand, $15 \mathrm{~km}$ southwest of Copenhagen, Denmark was studied. The housing estate consists of 12 high-rise buildings with 16 floors, 66 building blocks with four floors and eight terrace houses with two floors (Ellgaard, n.d.). Five of the 12 high-rise buildings are contaminated with PCB to such an extent that the threat posed by the PCB should be handled immediately according to the action value proposed by the authorities and presented in Table 1. Thus, this paper focuses on these five buildings (Ellgaard, n.d.), which holds around 300 apartments (Gudmand, 2015).

In the contaminated apartments the primary sources of PCB are located in flexible joints around windows and in sealant residues on the floor (Sparvath et al., 2014). The primary sources are indicated in Figure 1. The sealant used in the apartments contains up to $250.000 \mathrm{mg} \mathrm{PCB} / \mathrm{kg}$ (around 25\% PCB), which is a considerable concentration (Sparvath et al., 2014). 
Ohms, P., Andersen, C., Landgren, M., \& Birkved, M. (2018). Decision support for large-scale remediation strategies by fused urban metabolism and life cycle assessment. International Journal of Life Cycle Assessment (In Press). P.1-15. DOI: 10.1007/s11367-018-1445-9

Since PCB spreads to both the indoor and ambient environment, the interior of the apartments has been contaminated with PCB meaning that paint, wall materials, floors, doors, and furniture have become secondary sources of PCB. Thereby all rooms are considered contaminated with tertiary sources of PCB due to the contamination of indoor air by the primary and secondary sources. The contaminated rooms include rooms such as WCs and hallways that are not in direct contact with the primary sources of PCB. Some apartments contain high levels of PCB in the indoor air and the residents living in these critically contaminated apartments have thus been rehoused (Andersen, 2013). The residents in the five high-rise buildings in Broendby Strand are currently awaiting a renovation strategy to be decided upon. Meanwhile, a pilot project has been initiated and three compared remediation strategies - thermal desorption, steel blasting and sealing - were tested in vacant apartments in order to test which technique is the most cost efficient (Sparvath et al., 2014). Our paper investigates four remediation techniques considered for Broendby Strand:

- Thermal desorption

- $\quad$ Steel blasting

- Sealing

- $\quad$ Sand blasting.

The four remediation techniques were chosen since these are among the most commonly used in Denmark. Our paper is based on the assumption that the primary PCB sources (typically sealant) are removed before any of the four remediation techniques are applied.

By heating materials containing PCB to at least $50^{\circ} \mathrm{C}$, the PCB volatilizes from the material to the air and by subsequently using an air filter the PCB can be removed from the air compartment of an apartment - this technique is called thermal desorption (Koch et al., 2013). The techniques called steel blasting and sand blasting are very similar techniques. Both techniques use fine steel or sand particles which are blown at a surface at high speed, thereby stripping the contaminated material (Timm, n.d.) of the surface. The major difference between the two blasting techniques is that the sand grains can only be used once or twice whereas the steel grains can be reused up to 800 times (Interview: Kim Østergaard, J. Jensen A/S, 2016). Olsen et al. (2015) found that there is a great variety of blasting materials used for blasting. To cover this range in our study it was necessary to investigate two cases of both sandblasting and steel blasting - one case using a minimum amount of blasting material and one case using a maximum amount of blasting material.

The last technique assessed in our paper, sealing, simply works by applying a sealant to a surface and by doing so creating a permanent barrier layer that prevents the PCB from migrating to the indoor climate (Koch et al., 2013).

The selected remediation techniques differ significantly from each other in terms of labour effort, energy demand etc., which inevitably will make the environmental footprints of these techniques vary. To minimize the environmental burden of the renovation of Broendby Strand it is relevant to identify the most environmental friendly way of conducting a PCB-remediation. To do so the fused method of Urban Metabolism coupled with Life Cycle Assessment (UM-LCA) was applied to the case 
Ohms, P., Andersen, C., Landgren, M., \& Birkved, M. (2018). Decision support for large-scale remediation strategies by fused urban metabolism and life cycle assessment. International Journal of Life Cycle Assessment (In Press). P.1-15. DOI: 10.1007/s11367-018-1445-9

of renovating Broendby Strand. The idea is thereby to quantify the induced effects for each technique and life cycle stage. UM-LCA will hence be used as a tool to identify the most environmental friendly remediation technique and thereby function as a possible decision tool when choosing among PCB remediation strategies. Since cost and technical efficiency are the most important factors when choosing a remediation strategy these aspects will also be investigated and advantages and disadvantages for each technique will be identified and highlighted. By considering the technical, environmental and cost efficiency aspects of remediation techniques, a more holistic perspective on all remediation techniques should ideally be provided.

\section{Method}

To assess and prioritize the PCB-remediation techniques mentioned in the previous paragraph according to their environmental performance a combination of the methodology "Urban Metabolism" (UM) and the "Life Cycle Assessment" (LCA) framework was applied. In a traditional UM study, the city is typically depicted as a black box where up- and downstream induced burdens are kept outside of the study's scope (Goldstein et al., 2013). A UM study most often account for the material and energy flows necessary for a city to conduct its "metabolism" thereby yielding a liveable urban space. The metabolism and hence provision of the urban space can be compared to the "use stage" of an LCA. As illustrated in Figure 2, when the UM and LCA methodologies are combined, the LCA part is intended to account for environmental impacts of all life cycle stages by aggregating and characterizing the environmental loadings induced by inputs and emissions of the urban system conducting its metabolism (Goldstein et al., 2013). In our paper we apply the UM-LCA definition in accordance with the definition proposed by Goldstein et al. 2013. For our case specifically the UM-LCA term is used to reflect that the neighborhood undergoing renovation/remediation can, in accordance with the UM definition proposed by Wolman (1965), be regarded as a metabolic entity defining the foreground system of our LCA. The metabolic entity in UM-LCAs is hence controlling a range of value chains feeding the metabolic entity and handling the waste streams emitted by the metabolic entity. The metabolic entity and thus the foreground is therefore not representing a specific life cycle stage in a single value chain. The metabolic entity is moreover representing a range of life cycle stages within each value chain exploited by the metabolic entity. The UM-LCA is hence a way to apply long defined (urban) system assessment perspectives (i.e. urban metabolism) to describe a specific type of LCAs relying on a specific system perspective. By applying a combination of these two methods (UM-LCA) it is possible to calculate the environmental impact potentials of e.g. remediation techniques applied on urban or large neighbourhood level. In our study the area of interest are the five iconic PCBcontaminated multi-storage buildings located in Broendby Strand close to Copenhagen in Denmark. Due to the scale of the buildings, these were in our study considered as a neighbourhood. Only processes directly linked to the remediation are accounted for in our study. The included processes are summarized in Figure 3.

The goal of our assessment is to quantify the environmental impact induced by a number of PCB remediation techniques in order to provide a qualified decision support regarding the choice of refurbishment strategy. When carrying out such an assessment it is essential that the acquired data are 
Ohms, P., Andersen, C., Landgren, M., \& Birkved, M. (2018). Decision support for large-scale remediation strategies by fused urban metabolism and life cycle assessment. International Journal of Life Cycle Assessment (In Press). P.1-15. DOI: 10.1007/s11367-018-1445-9

based on the same unit (Jolliet et al., 2016). To ensure this, a functional unit was defined. In our assessment the functional unit was defined as provision of 1 average $\mathrm{m}^{2}$ remediated floor area with a PCB-concentration below the lowest action values i.e. below $300 \mathrm{ng} \mathrm{PCB} / \mathrm{m}^{3}$ air.

Hence, an inventory quantifying all extracted resources and emissions to the environment had to be made (Jolliet et al., 2016). Since the goal was to be able to compare the four remediation techniques, an inventory containing detailed data for each technique would be needed. All data were thus sorted according to product system of origin and location within the three life cycle stages - "raw materials", "execution of refurbishment" and "disposal". An example of such a product system can be seen in Table 2. In order to model these product systems in a comparative manner we interviewed experts to collect information on how the techniques are applied. The experts were not able to provide sufficient information on the techniques in order to build a complete inventory. Hence to fill out the data gaps, assumptions relating to the actual application of each technique had to be made. We made these assumptions based on existing literature, cases and projects. It was possible to find a relatively large amount of information in the literature however some details were simply not described or documented anywhere. Therefore, some of the data used in the simulations had to be based on assumptions made in accordance with our best judgment.

The data collected for the inventories of the remediation techniques were subsequently used to model a product system for each remediation technique. For this purpose, we used the software Quantis Suite 2.0 (QS2.0). QS2.0 is a simplified LCA product system modelling software, that calculates environmental impact potentials supported by background data from the Ecoinvent 2.2 inventory database (Humbert et al., 2012). Contrary to most other product system modeling software, QS2.0 does not allow for choosing between different impact assessment methods and using QS2.0 means having to rely solely on the IMPACT2002+ impact assessment methodology (Humbert et al., 2012).

Since QS2.0 relies on an older version of Ecoinvent and is a simplified product system modelling tool and since the systems being modelled are quite complex, we decided that it is necessary to validate the results and hence the decision support provided by QS2.0. In order to validate the results from QS2.0 we carried out the exact same assessment in a more complex tool; OpenLCA 1.5. It was chosen to use a more recent version of Ecoinvent for the validation; here Ecoinvent 3.2. By choosing a more recent version of Ecoinvent we intended to make sure that the decision support provided by QS2.0 not only aligns with more complicated product system modelling software but also more recent data. When using OpenLCA it is possible to choose between different impact assessment methods. Here we chose to use the ReCiPe 2000 midpoint and endpoints comparable to the results obtained from QS2.0. OpenLCA is an open source software and hence provided free of charge, which makes it an economical reachable tool to use in practice for architectural offices and other consultancies. However, the complexity of the tool can make it difficult and time consuming to use in design processes where the aim is to promote and facilitate knowledge based design decisions. Therefore, the current study emphasizes to investigate whether the complexity of OpenLCA are comparable to the results and hence if QS2.0 would be an acceptable choice of software to be used for simple and quick calculations in relation to building design practice. 
Ohms, P., Andersen, C., Landgren, M., \& Birkved, M. (2018). Decision support for large-scale remediation strategies by fused urban metabolism and life cycle assessment. International Journal of Life Cycle Assessment (In Press). P.1-15. DOI: 10.1007/s11367-018-1445-9

One of the challenges encountered in relation to comparison of the four techniques was that in practice using only one remediation technique is rarely enough to lower the PCB-level below action levels (Koch et al., 2013). As earlier mentioned usually several remediation techniques are used simultaneously and it is almost impossible to predict exactly how the preparations for a PCBremediation will take their course (Interview: Kim Østergaard, J. Jensen A/S, 2016). In our case we decided to investigate the techniques separately. Some denominators common to all remediation techniques were not included. The common denominators are the stripping of existing fixtures, removal of flooring and removal of the primary sources of PCB in each apartment. These are all actions that will represent an environmental impact when carried out - for instance, the disposal of all PCB-contaminated building materials will induce significant environmental effects - but since these actions are carried out before any of the techniques can be applied and since the actions are common to all techniques, it can be argued that the environmental impacts induced by these actions will be equally divided between the techniques and thus have negligible influence on the remediation technique comparison.

Even though the four remediation techniques all vary in the way they handle PCBcontamination, they share some further elements that we have chosen not to include in the comparison of the techniques. Identical elements of the techniques will not have any relative influence when comparing the results (Jolliet et al., 2016), they will only make the calculations more extensive and will require further data. An element, which reoccurs in every technique is e.g. an on-site changing room for workers, which ensures that traces of PCB on clothes is not spread. In Denmark, having an on-site changing room is compulsory when dealing with dangerous substances and therefore this changing room is an element identical for all remediation techniques.

Finally, we chose not to include activities, which - by our estimates - only induce minor/negligible environmental impacts. These activities include manufacturing of safety equipment and cleaning of handheld tools after the refurbishment of all apartments is finished.

The assumption that all of the above mentioned elements can be left out of the simulation has helped limiting the data processing needs. Besides this, limiting the number of activities simulated, so that only the activities differing across scenarios are left, can be considered an advantage in terms of result interpretation. It is easier to identify weaknesses and strengths for each remediation technique and thereby exposing possible ways of optimizing the techniques if only differences are compared. However, it is important to keep in mind that the estimated environmental impact potential for each technique is hence a relative measure and smaller than the "absolute” impact potential associated with a PCB-remediation technique. The absolute environmental impact potential could be calculated by adding environmental impacts associated with the activities not included in our results for each technique.

The focus of our paper is the environmental impact potentials associated with various PCBremediation techniques, however decisions relating to refurbishment strategy are, as earlier mentioned, rarely based on environmental performance arguments. Deciding which remediation technique(s) to use will in most cases be determined by cost (Interview: Kim Østergaard, J. Jensen A/S, 2016 ; Interview: Flemming Correll Frank, 2016 ; Interview: Kathrine Birkemark Olsen \& Lene Dalvang, 
Ohms, P., Andersen, C., Landgren, M., \& Birkved, M. (2018). Decision support for large-scale remediation strategies by fused urban metabolism and life cycle assessment. International Journal of Life Cycle Assessment (In Press). P.1-15. DOI: 10.1007/s11367-018-1445-9

2016). Rough estimates of the price for two out of the four techniques were found, however, as earlier mentioned it is difficult to predict how the exact course of a PCB-remediation will be which is why it is also difficult to predict the cost of a technique in advance.

\section{Results}

As mentioned earlier, this study considers two quite similar cases of the sand blasting and steel blasting techniques. For these techniques two sub-scenarios were assessed representing the use of a minimum amount of blasting material and a case where a maximum amount is used (Olsen et al., 2015).

Figure 4 presents the overall results for the case where a minimum amount of blasting material is used for the blasting techniques whereas Figure 5 illustrates the environmental impact potentials induced by the four techniques in the case where a maximum amount of blasting material is used. The two figures compare the four techniques and their environmental impact potentials. Figure 6A to Figure 6E compares the environmental impact in each endpoint category.

In Figure 4 and Figure 5, it can be seen that the technique thermal desorption is the remediation technique with the best environmental performance across most endpoint categories. The technique thermal desorption has the advantage that it does not produce any waste, which is an important reason for the environmental performance. As seen in Figure 7 it is the life cycle stage "execution of refurbishment" that exhibit the largest environmental impact potentials caused by the energy consumption induced by the elevation of the temperature in the building to minimum $50^{\circ} \mathrm{C}$. The life cycle stage "raw materials" represent a large environmental impact as well. A way of optimizing this stage could be to choose different materials than plywood as shielding during the remediation, due to a great environmental impact generated by the glue used in plywood (Teknologisk Institut, 2009).

Figure 4 and Figure 5 clearly illustrates that sand blasting is the technique inducing the largest environmental impact potentials in both cases using either minimum or maximum amounts of blasting material. As it can be seen in Figure 8 the life cycle stage "disposal" is clearly the life cycle stage exhibiting the largest impact potentials. Further analysis reveals that the majority of impacts, induced by sand blasting, are associated with the amount of construction waste and blasting material that needs to be disposed of as hazardous waste. Compared to the impacts from the construction waste, the blasting material constitutes only a minor part of the total environmental impact of sand blasting. From this it can be seen that it would be relevant to optimize the method of disposal and thereby reduce the environmental burden associated with the technique sand blasting.

Similar to sand blasting, the technique steel blasting has a great environmental impact. As it can be seen in Figure 9 the life cycle stage "disposal" is the most injurious to the environment. The great environmental impact in the disposal-stage is a result of the amount of construction waste that needs to be disposed of as hazardous waste.

Eventually, in Figure 4 and Figure 5 it is observed that the technique sealing has a noticeable low environmental impact. Figure 10 clearly illustrates that the life cycle stage "raw materials" causes the greatest impact associated with the use of surface sealant. The surface sealant is based on epoxy resin, which is known to be environmentally (both ambient and work) problematic (Huang et al., 2012) 
Ohms, P., Andersen, C., Landgren, M., \& Birkved, M. (2018). Decision support for large-scale remediation strategies by fused urban metabolism and life cycle assessment. International Journal of Life Cycle Assessment (In Press). P.1-15. DOI: 10.1007/s11367-018-1445-9

and it would hence be relevant to use a surface sealing alternative that is less problematic. An advantage of choosing this technique is that this solution does not produce any waste, just like the technique thermal desorption, which turned out to be an important factor having considerable influence on the total environmental impact of the compared remediation techniques.

Since QS2.0 is a simplified product system modelling software the exact same simulation conducted in QS2.0 were reproduced in OpenLCA using the same inventory data for all six techniques/foreground systems - sealing, sand blasting, steel blasting and thermal desorption. The results obtained from the two modelling approaches are hence not directly comparable for all impact categories (however assuming more or less direct comparability of simpler impact indicators such as GWP) however, it considered valid to compare the environmental ranking obtained for the remediation techniques considered and hence the decision support provided by the two product system modelling software.

Figure 11 presents the environmental impact potentials obtained for the four technics for the cases where a minimum of blasting material is used while Figure 12 shows the environmental impact of the four technics for the cases where a maximum amount of blasting material is used.

Figure 13A presents the environmental impact potentials for Climate Change and Figure 13E shows Water Depletion for all six remediation strategies. Figure 13B presents the ReCiPe endpoint categories for Ecosystems, Figure 13C Human Health and Figure 13D Resources. All five ReCiPe result sets are compared with the results obtained from QS2.0.

The compared remediation strategies are for the product system modelling software comparison divided into the three phases: "raw materials", "execution” and "disposal”.

Figure 14 shows the environmental impact potentials induced by thermal desorption, Figure 15 from sand blasting min, Figure 16 from steel blasting min and Figure 17 presents the relative environmental impacts from surface sealing.

\section{Efficiency of the techniques}

As mentioned in the paragraphs Introduction and Method deciding on a remediation strategy will in most cases be based on cost and efficiency of the remediation strategies (Interview: Flemming Correll Frank, 2016, Interview: Kathrine Birkemark Olsen \& Lene Dalvang, 2016, Interview: Kim Østergaard, J. Jensen A/S, 2016). As earlier mentioned in this paper a project where the efficiency of three compared remediation strategies had been tested. Determining the efficiency of a technique is challenging, due to the fact that the efficiency of a technique is highly dependent on which material the PCB needs to be removed from as well as the amount of PCB in the material. The next paragraph describes how the remediation of two apartments where carried out step by step.

Initially, the primary sources of PCB were removed from the apartments, which caused the concentration of PCB in the indoor air to decrease with $57 \%$ in one apartment and $71 \%$ in a second apartment (Sparvath et al., 2014). After removal of the primary sources, a steel blasting of all walls in the apartments was performed, which, at first, further lowered the PCB-concentration with additionally $2 \%$, but in one of the apartments the concentration rapidly increased again - possibly due to a 
Ohms, P., Andersen, C., Landgren, M., \& Birkved, M. (2018). Decision support for large-scale remediation strategies by fused urban metabolism and life cycle assessment. International Journal of Life Cycle Assessment (In Press). P.1-15. DOI: 10.1007/s11367-018-1445-9

mobilization of the PCB (Sparvath et al., 2014). After the steel blasting of the apartments a thermal desorption was conducted in one of the apartments, which made the concentration initially decrease with additionally 14\% (Sparvath et al., 2014). Over a longer time span the PCB-concentration in the indoor air however increased again, which may be due to the fact that an increase in temperature can mobilize the PCB and thereby cause an increase in PCB-concentration in the indoor air. In the second apartment a surface sealing was carried out which decreased the concentration with additionally $10 \%$ (Sparvath et al., 2014). The combination of removal of primary sources, steel blasting and a thermal desorption or a surface sealing respectively yields a total decrease in PCB-concentration of $49 \%$ (final = thermal desorption) in one apartment and 73\% (final step = surface sealing) in another (Sparvath et al., 2014). The total decreases presented here accounts for the unintended increases in concentration associated the steel blasting and thermal desorption techniques.

\section{Discussion and conclusions}

During this project it was challenging to locate the data necessary to conduct a UM-LCA on each technique. Because of this, a range of assumptions had to be made which has introduced uncertainties in the obtained via our assessment, and this fact needs to be accounted for in the interpretation of the result.

Our study indicates that the least environmentally burdensome technique is, thermal desorption (see Figure 4 and Figure 5). Some sources of errors could be that it in most cases will be necessary to perform a thermal desorption more than once as well as elevating the desorption temperature beyond $50^{\circ} \mathrm{C}$ (Koch et al., 2013) in order to obtain sufficient desorption. The higher temperature will inevitably cause a higher energy consumption and thereby make the technique more environmentally taxing. Through our assessment, it has been made clear that disposal of waste has a considerable influence on the total environmental performance of a remediation technique which provide the techniques generating the lowest amount of waste an environmental advantage.

The fact that the steel grains used for blasting in the technique steel blasting can be reused up to 800 times, was not, as initially expected, an advantage. This is due to the environmental impacts induced by the disposal of waste. Steel blasting is a relatively new remediation technique making it difficult to locate adequate data needed to conduct the assessment and thereby considerable uncertainties arise. In our project many of the assumptions regarding steel blasting are based on data found on sand blasting.

For sand blasting as was the case for steel blasting, it is the amount of disposed waste that affects the environmental performance the most. For both techniques the amount of waste depend on the PCB contamination levels and hardness of the contaminated material to be blasted, which yields uncertainties regarding the amount of waste for disposal.

Finally, the technique surface sealing encloses the PCB in the material and prevents it from migrating to the indoor environment. Thereby, the PCB will migrate further into the materials and over time contaminate a greater volume of the material (Koch et al., 2013). This will in the end increase the amount of hazardous waste to be disposed of when the contaminated building is demolished and it will hence be more difficult to separate the non-hazardous waste from the hazardous waste. However, new 
Ohms, P., Andersen, C., Landgren, M., \& Birkved, M. (2018). Decision support for large-scale remediation strategies by fused urban metabolism and life cycle assessment. International Journal of Life Cycle Assessment (In Press). P.1-15. DOI: 10.1007/s11367-018-1445-9

techniques might appear in the future, which will make the environmental impact associated with waste disposal smaller and justifying temporary solutions such as surface sealing. It would have been relevant to include the future demolition of the buildings and calculate the total environmental impact. Had this been included it is expected that the surface sealing technique would have performed significantly worse compared to the other techniques.

Comparing the two pieces of product system modelling software, QS2.0 and OpenLCA, underlines the efficiency of the simple tool QS2.0 as the results obtained from the two tools more or less are the same, with a maximum of $10 \%$ of variation. At the same time, by verifying the results obtained from QS2.0 by comparison with results obtained from OpenLCA it is ensured that the results remain unbiased and partially validated. The results obtained from OpenLCA proved in general to be lower than the QS2.0 results. An important difference lies in the impact assessment methods applied in the two programs resulting in different impact categories for quantification of the environmental performance of the remediation systems. It is concluded that the simpler simulation software QS2.0 is just as suited for the UM-LCA task as the more complex software OpenLCA and application of the tool may prove beneficial in practice due to ease of use and license price. However, the limitations (i.e. in terms of data resolution e.g. midpoints), choice of characterization method, availability of compatible inventory data) of QS2.0 also have to be taken into account when conducting a UM-LCA. Therefore, it is considered crucial to include a validating comparison applying a more conventional product system modelling software, here OpenLCA. Such a comparison ensures objectivity and hence validity of the statements made regarding QS2.0.

\section{Discussion of cost and efficiency}

As mentioned earlier the remediation techniques thermal desorption, steel blasting and sealing reduced the PCB contamination levels in two identical apartments with $73 \%$ and $49 \%$. Since the two apartments were identical the results should ideally not vary much. The noticeable variation in the results underline the difficulty in predicting the efficiency of the techniques and it is considered necessary to measure and validate the efficiency of each remediation technique in the respective apartments to get a clearer picture of exactly how efficient they are. The pilot project involving the two test apartments illustrates that the removal of primary contamination sources is the most efficient method and that the remediation techniques does not necessarily provide acceptable PCB contamination levels and hence acceptable low air concentrations. The best results can most likely be obtained through removal of the primary sources followed by a combination of the different techniques. Furthermore, the pilot project states that the remediation techniques thermal desorption and surface sealing are the most efficient techniques, but the risk of the PCB contamination forcing its way deeper into the construction materials needs to be considered.

Predicting the remediation cost is just as difficult as predicting the efficiency. The expenses related to the technique sand blasting varies from $450 \mathrm{DKK} / \mathrm{m}^{2}$ to $2.455 \mathrm{DKK} / \mathrm{m}^{2}$. The fact that data are available on this technique is due to the fact that this method is fairly common and it is therefore easier to obtain estimates of the expenses related to it. On the contrary there is currently only one Danish contractor applying the technique steel blasting and they reported that the average expenses related to 
Ohms, P., Andersen, C., Landgren, M., \& Birkved, M. (2018). Decision support for large-scale remediation strategies by fused urban metabolism and life cycle assessment. International Journal of Life Cycle Assessment (In Press). P.1-15. DOI: 10.1007/s11367-018-1445-9

the technique are $871 \mathrm{DKK} / \mathrm{m}^{2}$, which puts the expenses related to steel blasting within the price range of sand blasting yielding a clouded picture in terms of economic advantage of any of the methods.

It has not been possible to find reliable prices on the remaining techniques, thermal desorption and sealing, which complicates an economic and hence a more holistic comparison.

\section{UM-LCA as a decision tool}

One of the goals of this paper was to investigate how the method UM-LCA can function as a decision support tool in relation to a PCB remediation and if a simplified readily available product system modelling software are up for the task. The benefit of coupling UM with LCA is that the LCA will ensure that up- and downstream burdens are included in the assessment and the result will thereby become more accurate. In the same manner the UM framework compliments the LCA framework by providing a valuable and long defined (Wolman,1965) urban assessment framework perfectly compatible with a specific way of assessing (product) systems and, in our case more specifically, urban sub-systems“

In this study it has become clear that the amount of hazardous waste that needs to be disposed of by application of blasting based remediation techniques is a very relevant factor when prioritizing remediation techniques according to environmental burden. Since disposal of waste is an example of a downstream process that would be left out of a traditional UM-study, it can be concluded that without the combination of Urban Metabolism and Life Cycle Assessment the final result of this study could have been too narrow and hence misleading.

Applying the UM-LCA approach to the case of comparing different techniques has worked well and has successfully given an overview of which techniques are the best seen from an environmental point of view. Another way of assessing the environmental impacts of the renovation is described in the recently introduced Danish industry guidance for LCA on retrofit projects "Branchevejledning i LCA ved renovering” (see Worm et al. (2016)). Here, three levels of LCAs are proposed for retrofit projects. For each of the three levels, different life cycle stages are included in the assessment. The applied UM-LCA methodology in this study would be (approximately) comparable to a level 2 LCA according to the new guidance, however since the study described here was carried out as a comparative LCA, certain life cycle stages that the guidance normally recommends to include, were purposely left out (since these are assumed equal for the systems compared). Examples of life cycle stages that could be left out in our comparative LCA are e.g. disposal demolished building materials, the PCB contaminated floor boards and window frames etc. A UM-LCA is roughly speaking merely a specific form of (building) project LCA relying both on the LCA framework and the already defined (Wolman, 1965) UM framework in order to project the correct system perspective applied for the assessment. When comparing the considered techniques, the result is straightforward and easy to comprehend and communicate with little or no prior knowledge of LCA required. As a part of our consideration of UM-LCA as a useful tool for decision support, four experts were asked about their opinion on the possibility of incorporating results from an LCA in a remediation decision process (Interview: Kim Østergaard, J. Jensen A/S, 2016 ; Interview: Flemming Correll Frank, 2016 ; Interview: Kathrine Birkemark Olsen \& Lene Dalvang, 2016). Of the four experts three were 
Ohms, P., Andersen, C., Landgren, M., \& Birkved, M. (2018). Decision support for large-scale remediation strategies by fused urban metabolism and life cycle assessment. I nternational Journal of Life Cycle Assessment (In Press). P.1-15. DOI: 10.1007/s11367-018-1445-9

dismissive of the idea and argued that cost and efficiency of a refurbishment strategy always would be the determining factors. Only one of the four experts was open to the idea of including UM-LCA as a support tool for decision-making. It was suggested that performing an LCA could be a service that consulting engineers and architects offer a building contractor. Given that three out of four responses were negative, it is clear that if environmental factors should gain priority when planning future refurbishment of large-scale projects, further (potentially legislative) incentives are needed.

A possible way of motivating contractors, consulting engineers, architects and building contractors to implement UM-LCA as a decision support tool could be to establish a financial incentive as is the case with DGNB certification. A study done by the World Green Building Council shows that the general perception in the Danish building industry is that sustainable buildings or "green" buildings causes higher expenses than what they really do (World Green Building Council, 2013). The same study disproves this perception by describing how a DGNB-certified building generally causes lower energy costs and fewer expenses related to operation and maintenance while at the same time increasing the rental income and sales value of the building and inducing higher efficiency amongst employees as a result of a better indoor climate (World Green Building Council, 2013). A Danish DGNB-certification was first introduced in 2012 and in the spring of 201550 projects were certified or in the process of being certified (Green Building Council Denmark, 2016). In April 2016 the Danish Green Building Council performed a market investigation, where 55 persons from 45 different companies answered a questionnaire about their opinion on sustainable buildings and DGNBcertification. $80 \%$ of the participants answered that they expect that the demand for sustainable buildings will increase and 0\% answered that they expect a decrease (Green Building Council Denmark, 2016).

With the above-summarized study in mind it can be argued that sustainability is and will most likely be a relevant parameter to most contractors in the future, but most likely only as long as some sort of financial gain is associated with the sustainability "tag". It is hence considered if the environmental impacts of a renovation or remediation technique could be incorporated as a parameter in a (renovation) certification such as DGNB. If one of the requirements for reaching a high (renovation) DGNB-score - and thereby gaining the possible financial reward associated with a DGNB-certified building - was documenting that the most environmental friendly renovation strategy had been chosen, contractors, consulting engineers, architects and building contractors would have an incentive for investigating and choosing the technique with the smallest environmental impact. Furthermore, it could be a criterion that the documentation should be in the form of a (UM-)LCA.

Finally, it can be concluded that UM-LCA is a highly applicable and highly illustrative tool that can and should be used as a decision support tool for building renovation/remediation and has the potential to be essential in the future of designing sustainable buildings, if some sort of economical aspect could become incorporated in/associated with the method.

\section{References}

Andersen, U. (2013). Giftige fuger: Fem højhuse skal renoveres for over en halv milliard kr. Retrieved 
Ohms, P., Andersen, C., Landgren, M., \& Birkved, M. (2018). Decision support for large-scale remediation strategies by fused urban metabolism and life cycle assessment. I nternational Journal of Life Cycle Assessment (In Press). P.1-15. DOI: 10.1007/s11367-018-1445-9

August 11, 2016, from https://ing.dk/artikel/giftige-fuger-fem-hoejhuse-skal-renoveres-over-enhalv-milliard-kr-156810

Dansk asbestforening. (2010). PCB Vejledning.

Ellgaard, L. (n.d.). Brøndby Strands historie. Retrieved August 12, 2016, from http://forstadsmuseet.dk/historien-om/broendby-strands-historie/

Goldstein, B., Birkved, M., Quitzau, M.-B., \& Hauschild, M. (2013). Quantification of urban metabolism through coupling with the life cycle assessment framework: concept development and case study. Environmental Research Letters, 8, 35024. https://doi.org/10.1088/17489326/8/3/035024

Green Building Council Denmark. (2016). Bæredygtigt byggeri, markedsundersøgelse.

Gudmand, J. (2015). Fem højhuse skal have fjernet PCB. Retrieved December 7, 2016, from http://sn.dk/Sydkysten/Fem-hoejhuse-skal-have-fjernet-PCB/artikel/463208

Humbert, S., Schryver, A. De, Bengoa, X., Margni, M., \& Jolliet, O. (2012). IMPACT $2002+$ : User Guide (Vol. Q2.21). Retrieved from http://www.presustainability.com/download/DatabaseManualMethods.pdf

Interview: Flemming Correll Frank. (2016). Retrieved December 2, 2016, from https://www.dropbox.com/sh/1m7u9qpvoq4leop/AAAi2Nl4qH5gxHuBPv_WcnKCa?dl=0

Interview: Kathrine Birkemark Olsen \& Lene Dalvang. (2016). Retrieved from https://www.dropbox.com/sh/1m7u9qpvoq4leop/AAAi2Nl4qH5gxHuBPv_WcnKCa?dl=0

Interview: Kim Østergaard, J. Jensen A/S. (2016). Retrieved December 2, 2016, from https://www.dropbox.com/sh/1m7u9qpvoq4leop/AAAi2Nl4qH5gxHuBPv_WcnKCa?dl=0

Jolliet, O., Saadé-Sbeih, M., Shaked, S., \& Jolliet, A. (2016). Environmental life cycle assessment.

Koch, A. P., Nielsen, P. A., \& Statens Byggeforskningsinstitut. (2013). Renovering af bygninger med PCB.

Olsen, K. B., \& Nerum Olesen, M. (2015). Metoder til fjernelse af miljøproblematiske stoffer.

Sparvath, M., \& Trap, N. (2014). Pilotprojekt Brøndby Strand, PCB sanering Brøndby Strand. Golder Associates A/S.

Sundhedsstyrelsen, Trafik- og Byggestyrelsen, Miljø- og Fødevareministeriet, Arbejdstilsynet, \& Udlændinge-, I. B. (2014). PCB-guiden, fakta om PCB. Retrieved August 19, 2016, from http://pcb-guiden.dk/fakta-om-pcb

Teknologisk Institut. (2009). Krydsfiner. Retrieved December 4, 2016, from http://www.trae.dk/leksikon/krydsfiner/

Timm, H. (n.d.). Sandblæsning. Retrieved December 2, 2016, from http://simpelenergi.dk/sandblaesning/ 
Ohms, P., Andersen, C., Landgren, M., \& Birkved, M. (2018). Decision support for large-scale remediation strategies by fused urban metabolism and life cycle assessment. International Journal of Life Cycle Assessment (In Press). P.1-15. DOI: 10.1007/s11367-018-1445-9

Wolman, A. (1965) The metabolism of cities. Scientific American, Volume 213, p. 179-90

World Green Building Council. (2013). The Business Case for Green Building, 124. Retrieved from http://www.worldgbc.org/activities/business-case/

Worm, A. S., Poulin, H., Østergaard, F. C., Birgisdottir, H., Madsen, S. S., \& Rasmussen, F. N. (2016). Branchevejledning i LCA ved renovering. 
Ohms, P., Andersen, C., Landgren, M., \& Birkved, M. (2018). Decision support for large-scale remediation strategies by fused urban metabolism and life cycle assessment. International Journal of Life Cycle Assessment (In Press). P.1-15. DOI: 10.1007/s11367-018-1445-9

\section{Tables}

Table 1 Action values/air concentrations defining when to act on PCB in the indoor climate (Sundhedsstyrelsen et al., 2014)

Above 3000 ng/PCB m3 air
Between 300-3000 ng/PCB m3 air

Below 300 ng/PCB m3 air
Long-term stay will cause a significant increased health risk and the concentration should be minimized immediately.

Can cause a health risk at long-term stays. The risk should be handled as soon as possible.

Health risk is insignificant and no action is needed. 
Ohms, P., Andersen, C., Landgren, M., \& Birkved, M. (2018). Decision support for large-scale remediation strategies by fused urban metabolism and life cycle assessment. I nternational Journal of Life Cycle Assessment (In Press). P.1-15. DOI: 10.1007/s11367-018-1445-9

Table 2 Representative remediation inventory: Inventory for the technique "thermal desorption"

\begin{tabular}{|c|c|c|c|c|c|c|}
\hline & \multirow[t]{2}{*}{ Raw materials } & \multirow[t]{2}{*}{$\begin{array}{c}\text { Execution of } \\
\text { renovation }\end{array}$} & \multicolumn{2}{|c|}{ Transportation } & \multirow[t]{2}{*}{ Disposal } & \multirow[t]{2}{*}{ Transportation } \\
\hline & & & $\begin{array}{c}\text { To } \\
\text { construction } \\
\text { site }\end{array}$ & $\begin{array}{c}\text { From } \\
\text { construction } \\
\text { site }\end{array}$ & & \\
\hline Rock wool & $0.79 \mathrm{~kg}$ & - & $0.006 \mathrm{tkm}$ & - & $0.79 \mathrm{~kg}$ & $0.09 \mathrm{tkm}$ \\
\hline Plywood & $0.0027 \mathrm{~m} 3$ & - & $0.011 \mathrm{tkm}$ & - & $1.365 \mathrm{~kg}$ & $0.16 \mathrm{tkm}$ \\
\hline Gloves & $0.0019 \mathrm{~kg}$ & - & & & & \\
\hline Coverall & $0.038 \mathrm{~kg}$ & - & 0.0099 tkm & - & $0.0497 \mathrm{~kg}$ & $0.006 \mathrm{tkm}$ \\
\hline A2P3 filter & $0.0093 \mathrm{~kg}$ & - & & & & \\
\hline Charcoal filter & $0.0015 \mathrm{~m} 3$ & - & $0.0135 \mathrm{tkm}$ & - & $0.075 \mathrm{~kg}$ & 0.0089 tkm \\
\hline Aircleaner, charcoal & - & $1.8 \mathrm{kWh}$ & $0.0002 \mathrm{tkm}$ & $0.0002 \mathrm{tkm}$ & - & - \\
\hline HEPA filter & $0.13 \mathrm{~kg}$ & - & $0.032 \mathrm{tkm}$ & - & $0.013 \mathrm{~kg}$ & $0.015 \mathrm{tkm}$ \\
\hline Aircleaner, HEPA & - & $1.8 \mathrm{kWh}$ & $0.00018 \mathrm{tkm}$ & $0.00018 \mathrm{tkm}$ & - & - \\
\hline Calorifere & - & $3.36 \mathrm{kWh}$ & $0.0011 \mathrm{tkm}$ & $0.0011 \mathrm{tkm}$ & - & - \\
\hline Oil furnace & - & $37.3 \mathrm{MJ}$ & 0.0003 tkm & 0.0003 tkm & - & - \\
\hline Fan & - & $0.84 \mathrm{kWh}$ & $0.00086 \mathrm{tkm}$ & $0.0022 \mathrm{tkm}$ & $0.019 \mathrm{~kg}$ & $0.0022 \mathrm{tkm}$ \\
\hline Vacuum cleaner & - & $0.04 \mathrm{kWh}$ & $0.00013 \mathrm{tkm}$ & $0.00013 \mathrm{tkm}$ & - & - \\
\hline
\end{tabular}


Ohms, P., Andersen, C., Landgren, M., \& Birkved, M. (2018). Decision support for large-scale remediation strategies by fused urban metabolism and life cycle assessment. International Journal of Life Cycle Assessment (In Press). P.1-15. DOI : 10.1007/s11367-018-1445-9

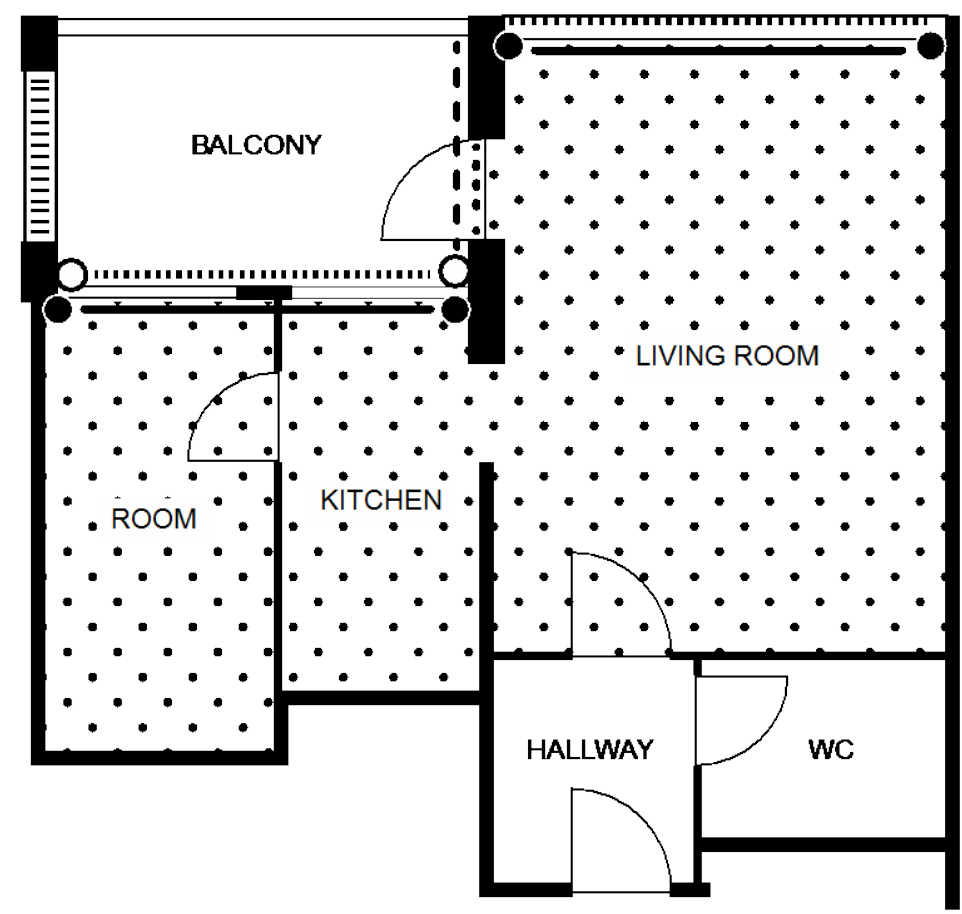

INTERNAL VERTICAL JOINT

INTERNAL JOINT, HORIZONTAL BOTTOM AND TOP

EXTERnAL Vertical JoInt

IIIIIII EXTERNAL JOINTABOVE WINDOW SECTION

- - EXTERNAL JOINT, BOtTOM

EXTERNAL JOINT AROUND DOORS AND WINDOWS

- SEALER RESIDUE ON FLOOR

Fig. 1 Illustration of an apartment in Broendby Strand with the PCB-sources highlighted (Sparvath et al., 2014) 
Ohms, P., Andersen, C., Landgren, M., \& Birkved, M. (2018). Decision support for large-scale remediation strategies by fused urban metabolism and life cycle assessment. International Journal of Life Cycle Assessment (In Press). P.1-15. DOI: 10.1007/s11367-018-1445-9
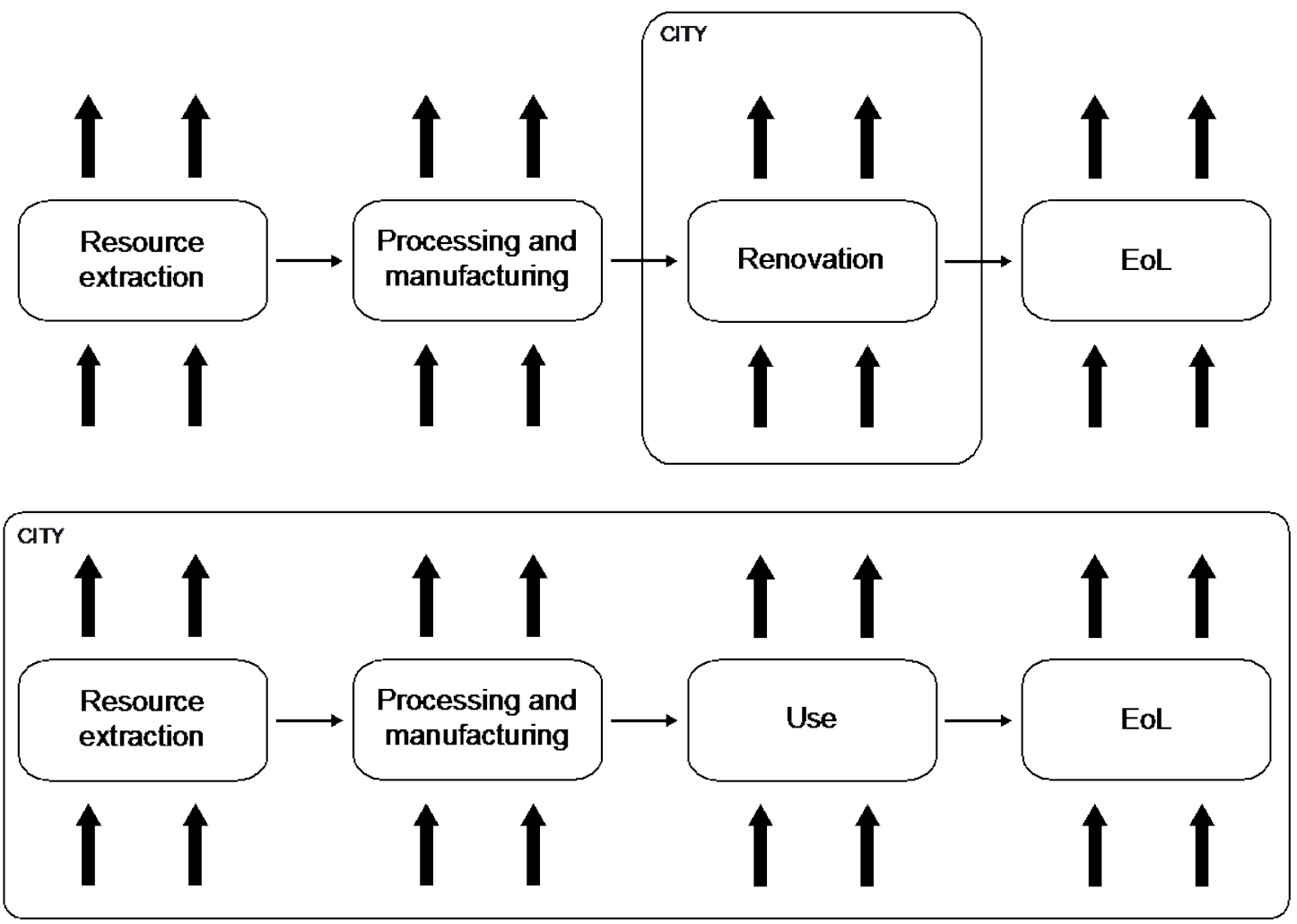

Fig. 2 Simplified illustration of how the scope of an urban LCA study can differ from system flows of materials at macro scale (top) and micro scale (bottom). This study is done by considering the flows at macro scale, where the physical delineation of the city/neighborhood forms the system boundaries of the renovation LCA. Based on Goldstein et al. (2013).” 
Ohms, P., Andersen, C., Landgren, M., \& Birkved, M. (2018). Decision support for large-scale remediation strategies by fused urban metabolism and life cycle assessment. International Journal of Life Cycle Assessment (In Press). P.1-15. DOI: 10.1007/s11367-018-1445-9

\begin{tabular}{lll}
\hline Life cycle stages & \multicolumn{2}{l}{ Process } \\
\hline Product phase & A1 & Extraction of raw material \\
& A2 & Transportation for manufacturing \\
& A3 & Manufacturing of materials \\
& A4 & Transportation to building site \\
Refurbishment & B1 & Stripping of fixture \\
& B2 & Sealing off \\
& B3 & PCB-remediation \\
& B4 & Cleaning \\
& B5 & Installation of fixture \\
& B6 & Water consumption \\
End-of-life & C1 & Transportation to disposal \\
& C2 & Incineration/landfill \\
Next inventory & D & Recycling/reuse potential \\
\hline
\end{tabular}

Fig. 3 The phases and process groups included in the LCA's carried out in this paper 
Ohms, P., Andersen, C., Landgren, M., \& Birkved, M. (2018). Decision support for large-scale remediation strategies by fused urban metabolism and life cycle assessment. International Journal of Life Cycle Assessment (In Press). P.1-15. DOI: 10.1007/s11367-018-1445-9

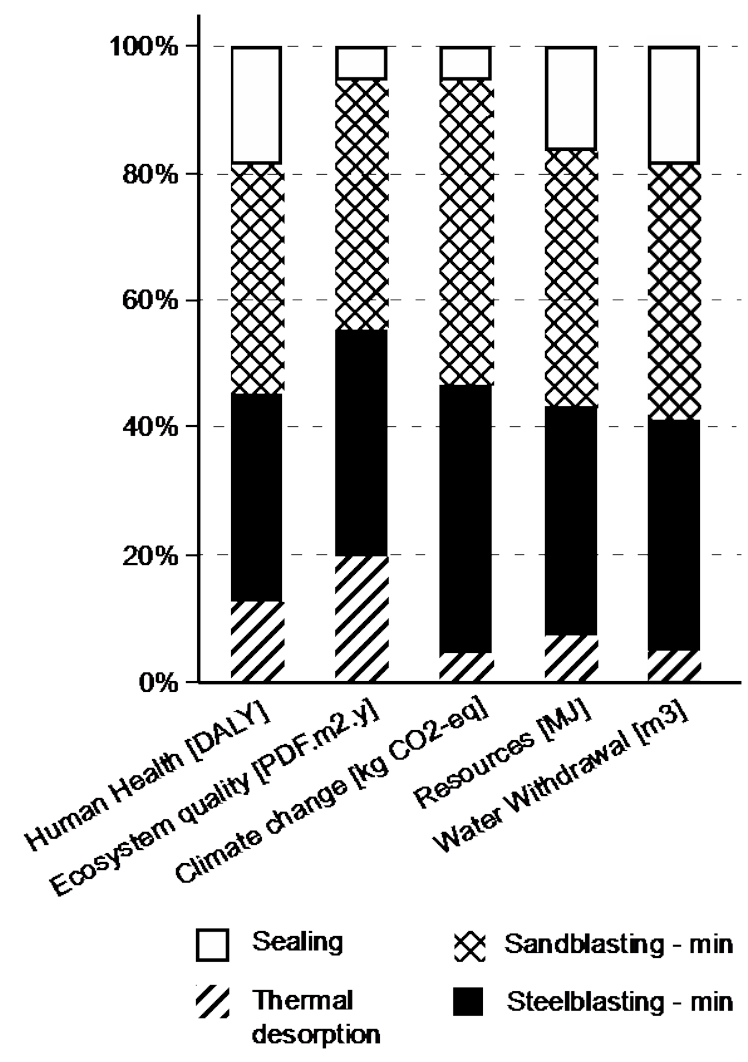

Fig. 4 Comparison of the considered PCB remediation techniques, assuming use of minimum amounts of blasting material for the two blasting techniques, Quantis Suite 2.0 
Ohms, P., Andersen, C., Landgren, M., \& Birkved, M. (2018). Decision support for large-scale remediation strategies by fused urban metabolism and life cycle assessment. International Journal of Life Cycle Assessment (In Press). P.1-15. DOI: 10.1007/s11367-018-1445-9

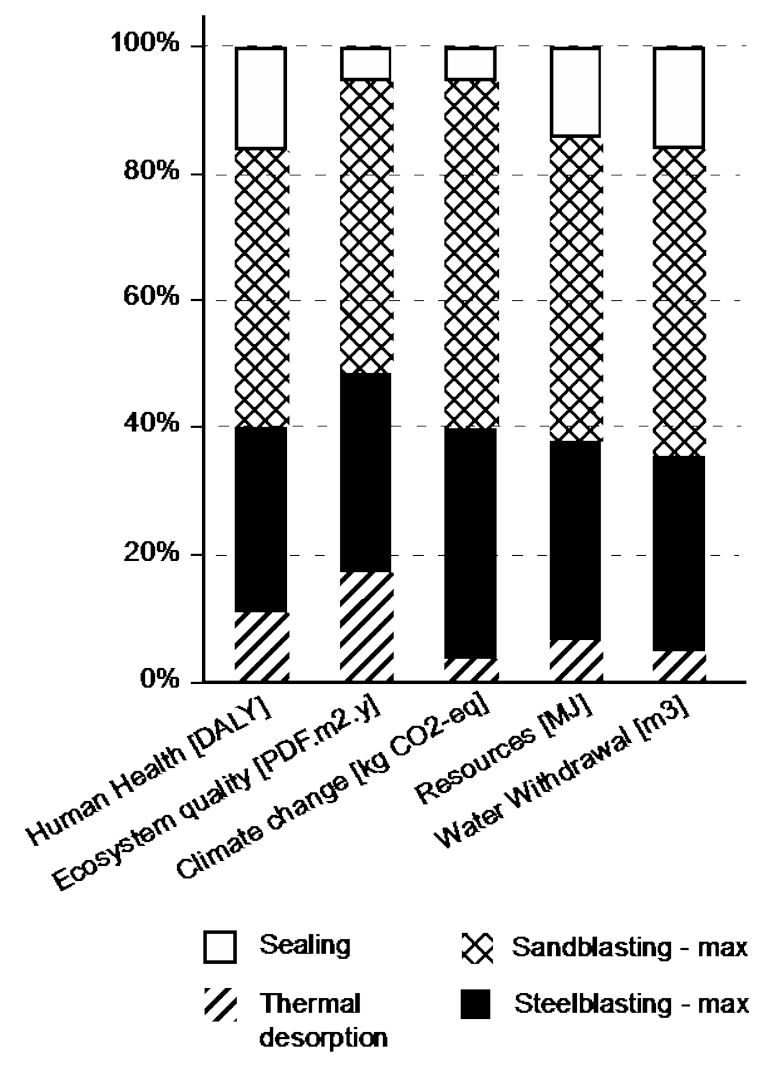

Fig. 5 Comparison of the considered PCB remediation techniques, assuming use of maximum amounts of blasting material for the two blasting techniques, Quantis Suite 2.0 
Ohms, P., Andersen, C., Landgren, M., \& Birkved, M. (2018). Decision support for large-scale remediation strategies by fused urban metabolism and life cycle assessment. I nternational Journal of Life Cycle Assessment (In Press). P.1-15. DOI: 10.1007/s11367-018-1445-9
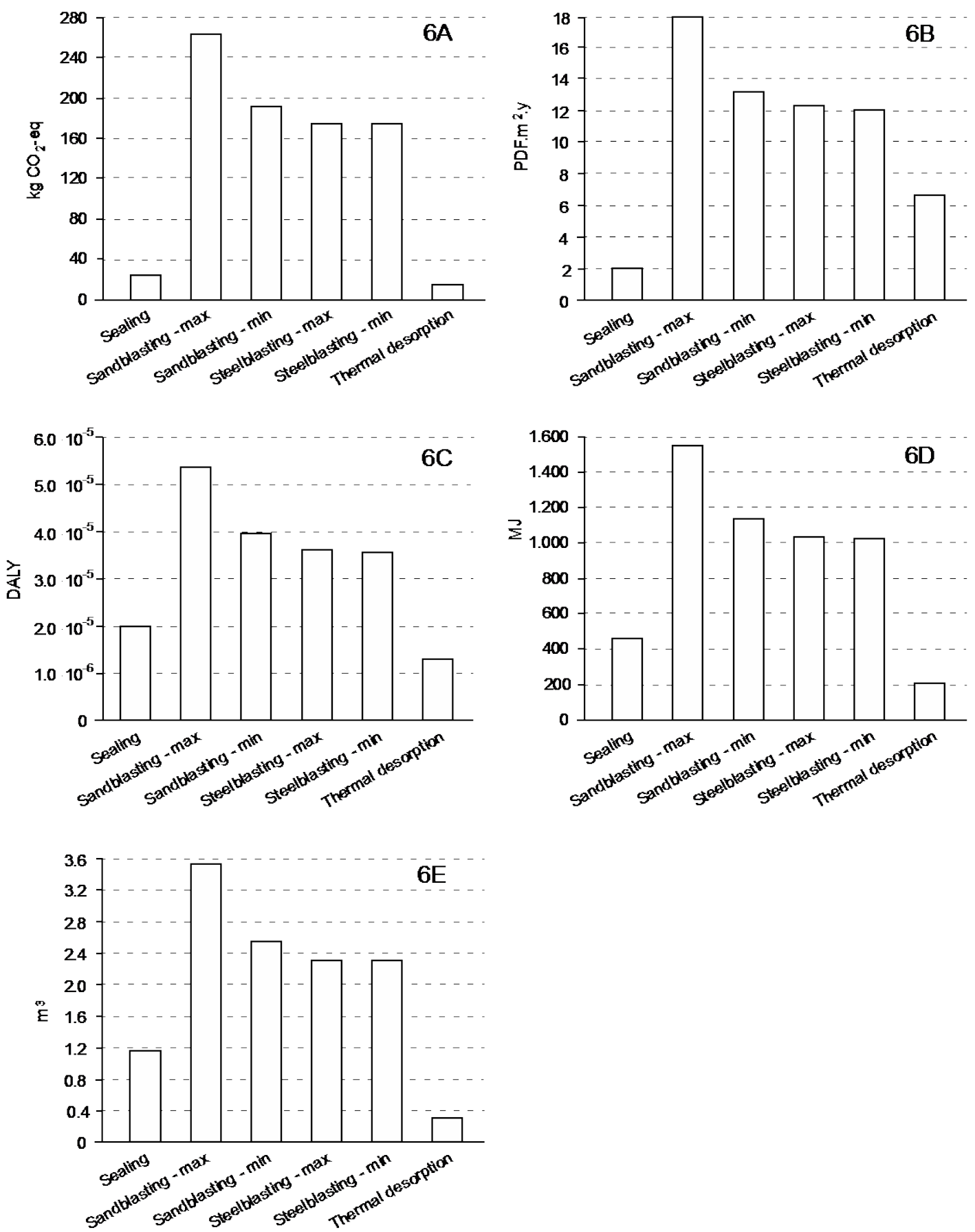

Fig. 6A IMPACT2002+ endpoint Climate Change, Fig. 6B IMPACT2002+ endpoint Ecosystem Quality, Fig. 6C IMPACT2002+ endpoint Human Health, Fig. 6D IMPACT2002+ endpoint Resources, Fig. 6E IMPACT2002+ endpoint Water Withdrawal 
Ohms, P., Andersen, C., Landgren, M., \& Birkved, M. (2018). Decision support for large-scale remediation strategies by fused urban metabolism and life cycle assessment. International Journal of Life Cycle Assessment (In Press). P.1-15. DOI: 10.1007/s11367-018-1445-9

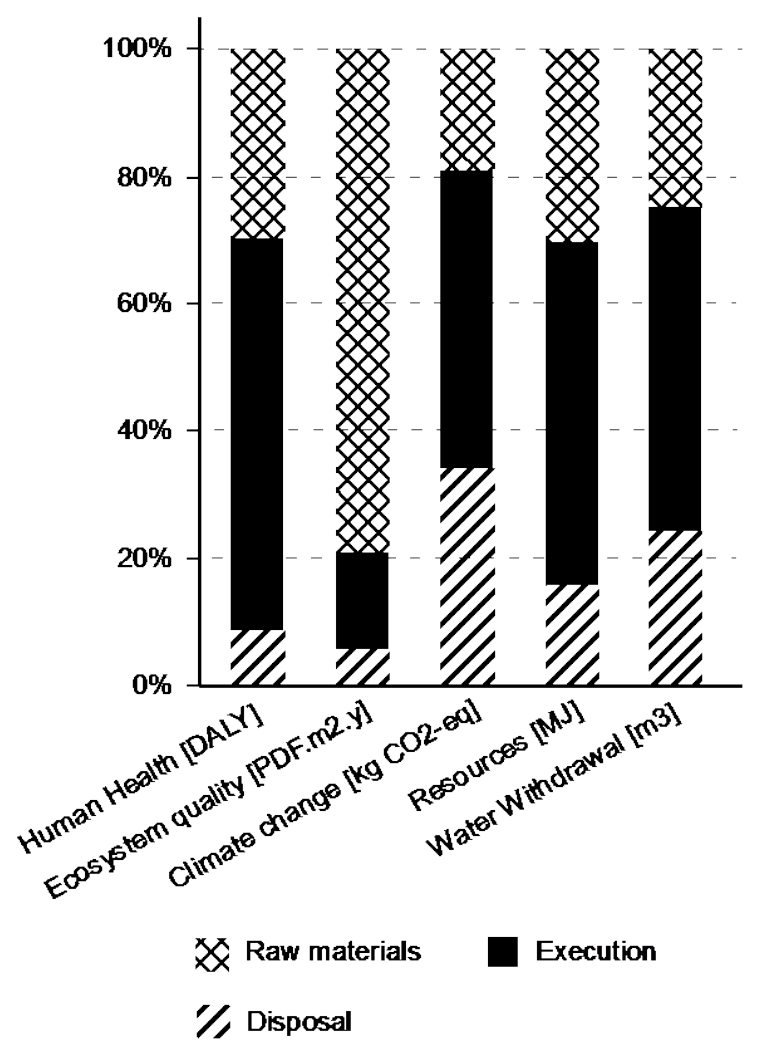

Fig. 7 Overview of the origin of the environmental impact potentials associated with thermal desorption, Quantis Suite 2.0 
Ohms, P., Andersen, C., Landgren, M., \& Birkved, M. (2018). Decision support for large-scale remediation strategies by fused urban metabolism and life cycle assessment. International Journal of Life Cycle Assessment (In Press). P.1-15. DOI: 10.1007/s11367-018-1445-9

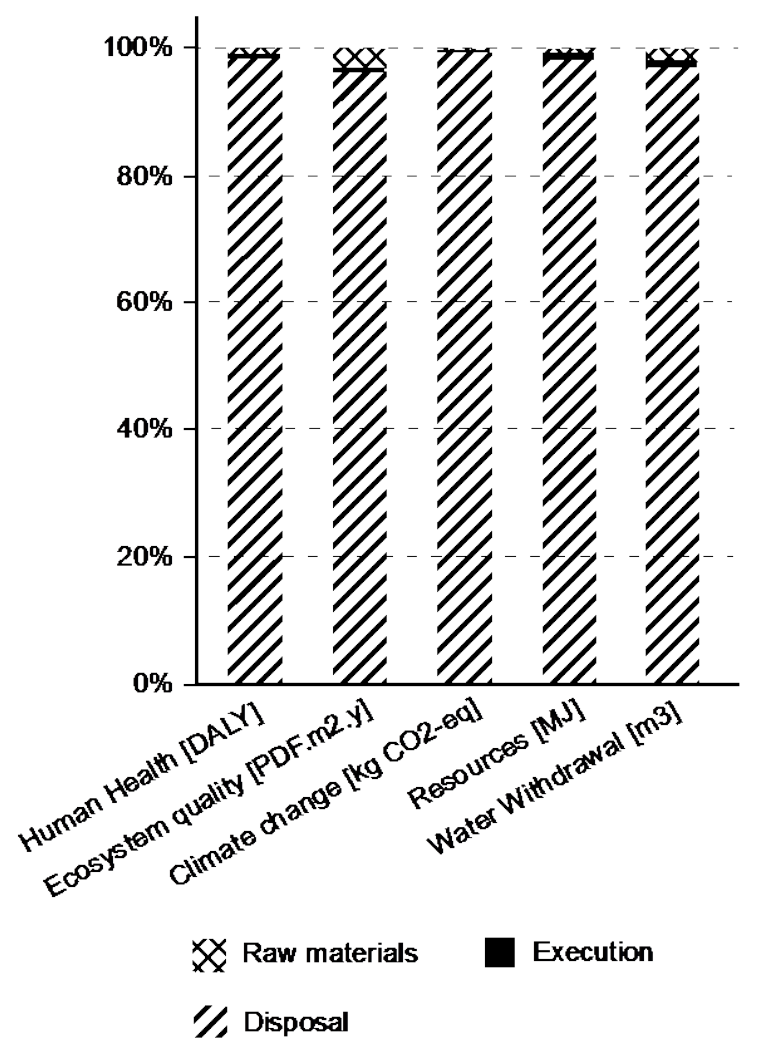

Fig. 8 Overview of the origin of the environmental impact potentials associated with sand blasting. Quantis Suite 2.0 
Ohms, P., Andersen, C., Landgren, M., \& Birkved, M. (2018). Decision support for large-scale remediation strategies by fused urban metabolism and life cycle assessment. International Journal of Life Cycle Assessment (In Press). P.1-15. DOI: 10.1007/s11367-018-1445-9

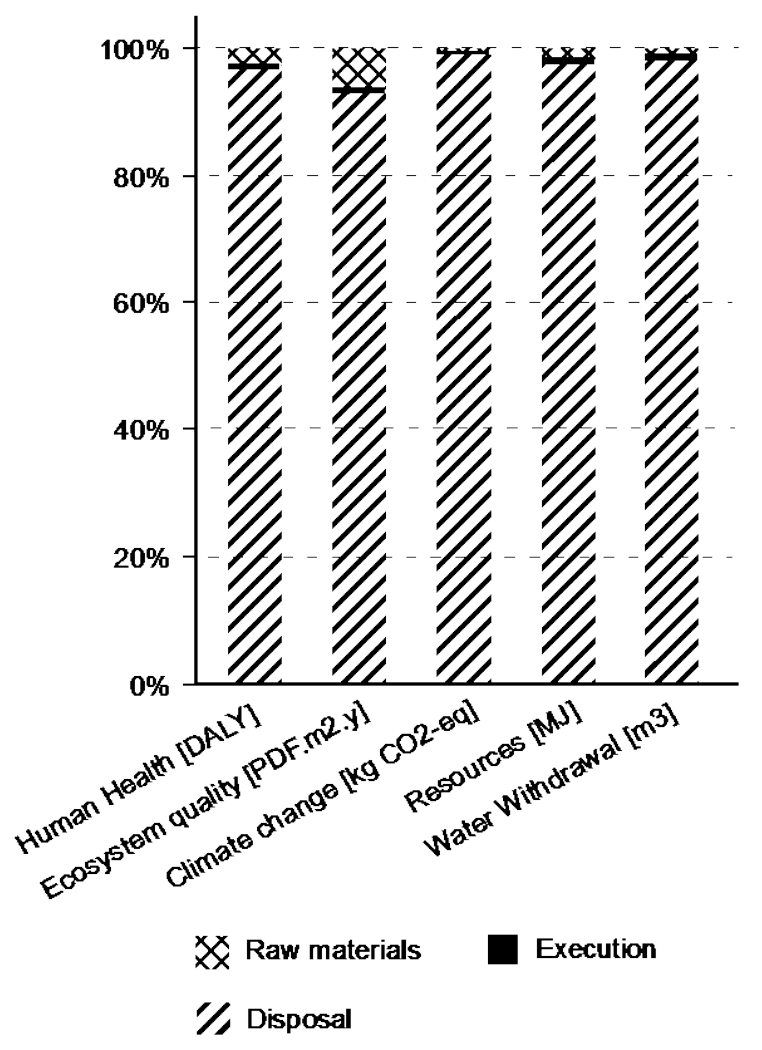

Fig. 9 Overview of the origin of the environmental impact potentials associated with steel blasting. Quantis Suite 2.0 
Ohms, P., Andersen, C., Landgren, M., \& Birkved, M. (2018). Decision support for large-scale remediation strategies by fused urban metabolism and life cycle assessment. International Journal of Life Cycle Assessment (In Press). P.1-15. DOI: 10.1007/s11367-018-1445-9

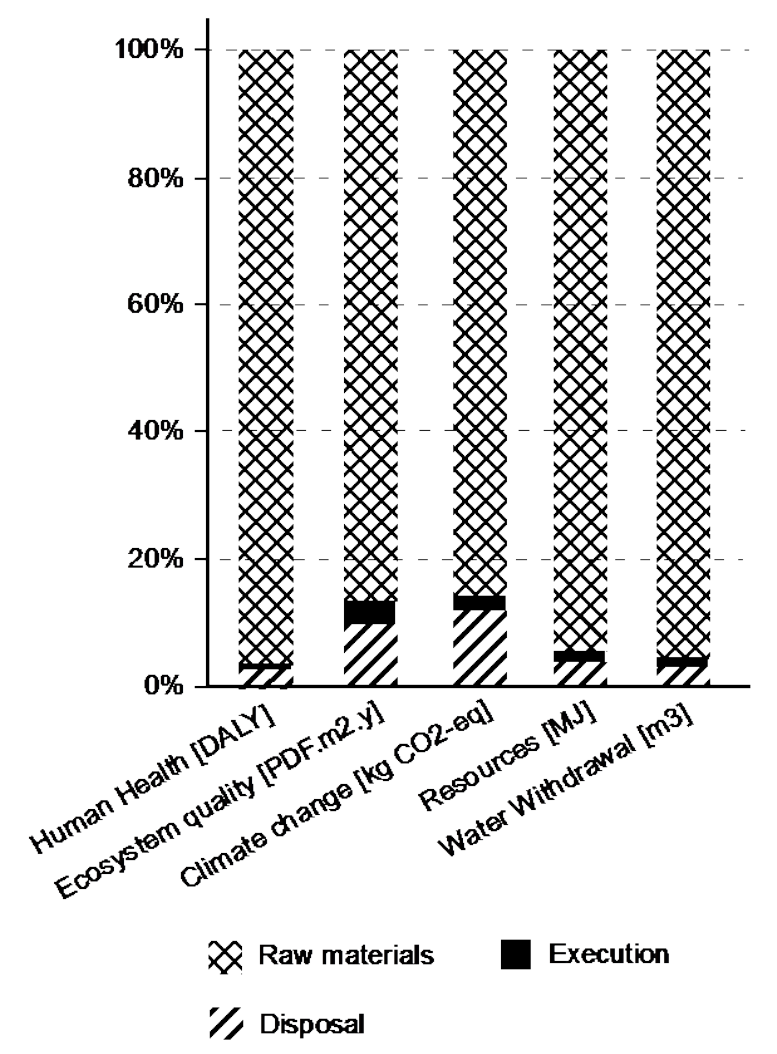

Fig. 10 Overview of the origin of the environmental impact potentials associated with surface sealing, Quantis Suite 2.0 
Ohms, P., Andersen, C., Landgren, M., \& Birkved, M. (2018). Decision support for large-scale remediation strategies by fused urban metabolism and life cycle assessment. International Journal of Life Cycle Assessment (In Press). P.1-15. DOI: 10.1007/s11367-018-1445-9

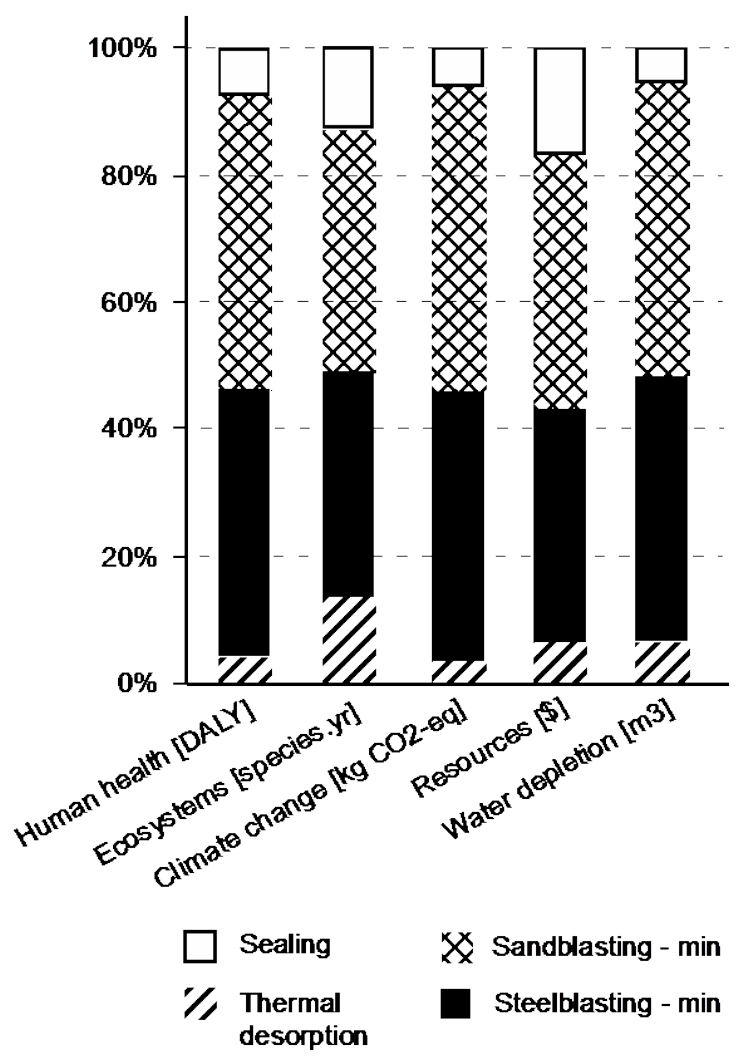

Fig. 11 Comparison of techniques, minimum amount of blasting material, OpenLCA 
Ohms, P., Andersen, C., Landgren, M., \& Birkved, M. (2018). Decision support for large-scale remediation strategies by fused urban metabolism and life cycle assessment. International Journal of Life Cycle Assessment (In Press). P.1-15. DOI: 10.1007/s11367-018-1445-9

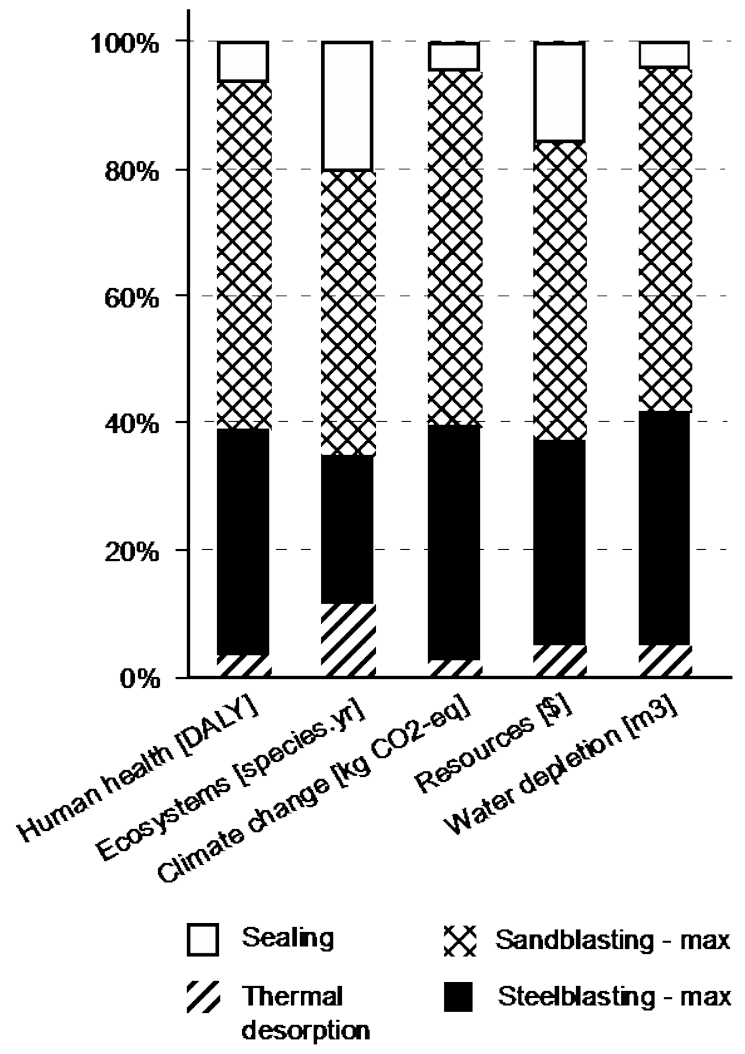

Fig. 12 Comparison of techniques, maximum amount of blasting material, OpenLCA 
Ohms, P., Andersen, C., Landgren, M., \& Birkved, M. (2018). Decision support for large-scale remediation strategies by fused urban metabolism and life cycle assessment. International Journal of Life Cycle Assessment (In Press). P.1-15. DOI: 10.1007/s11367-018-1445-9
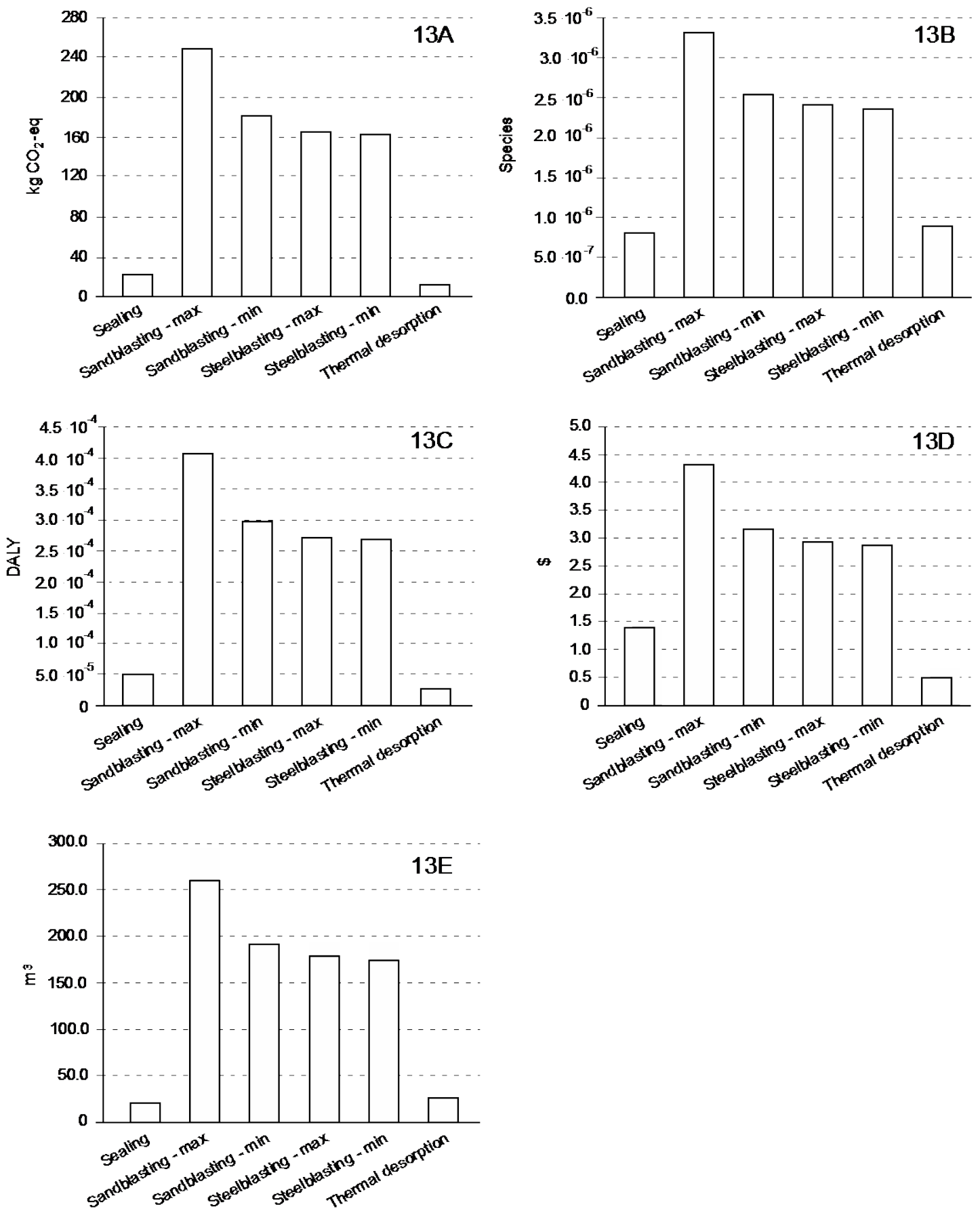

Fig. 13A Climate Change, OpenLCA, Fig. 13B Ecosystems, OpenLCA, Fig. 13C Human Health, OpenLCA, Fig. 13D Resources, OpenLCA, Fig. 13E Water Depletion, OpenLCA 
Ohms, P., Andersen, C., Landgren, M., \& Birkved, M. (2018). Decision support for large-scale remediation strategies by fused urban metabolism and life cycle assessment. International Journal of Life Cycle Assessment (In Press). P.1-15. DOI: 10.1007/s11367-018-1445-9

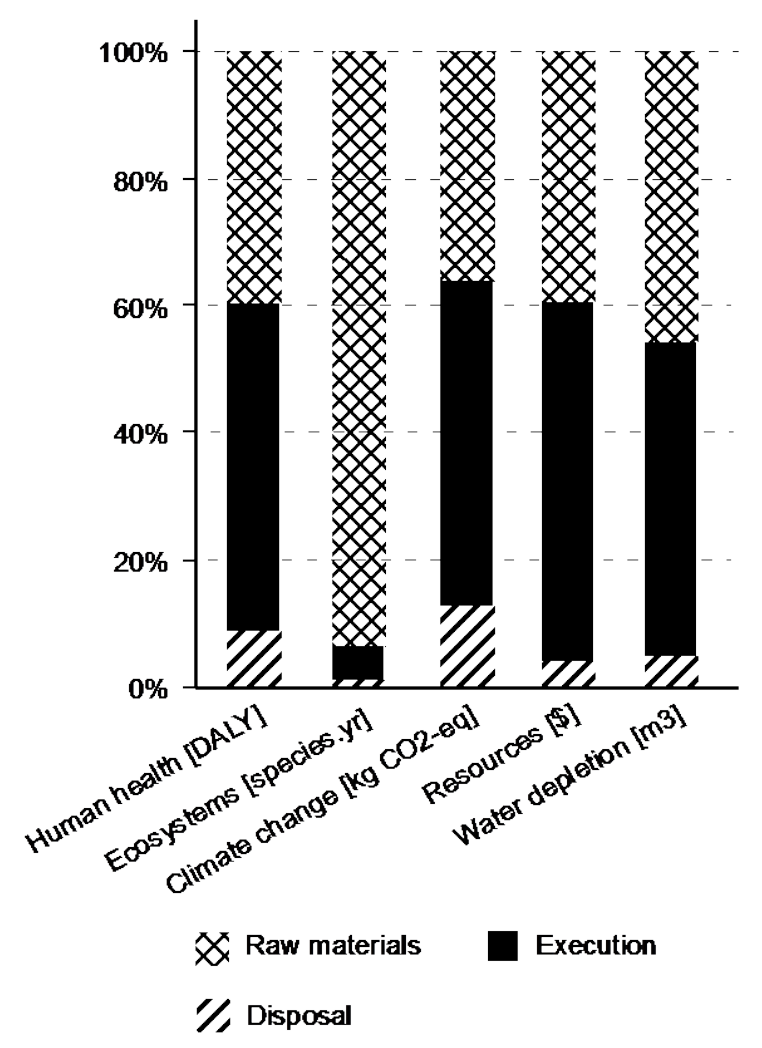

Fig. 14 Overview of the origin of the environmental impact potentials associated with thermal desorption, OpenLCA 
Ohms, P., Andersen, C., Landgren, M., \& Birkved, M. (2018). Decision support for large-scale remediation strategies by fused urban metabolism and life cycle assessment. International Journal of Life Cycle Assessment (In Press). P.1-15. DOI: 10.1007/s11367-018-1445-9

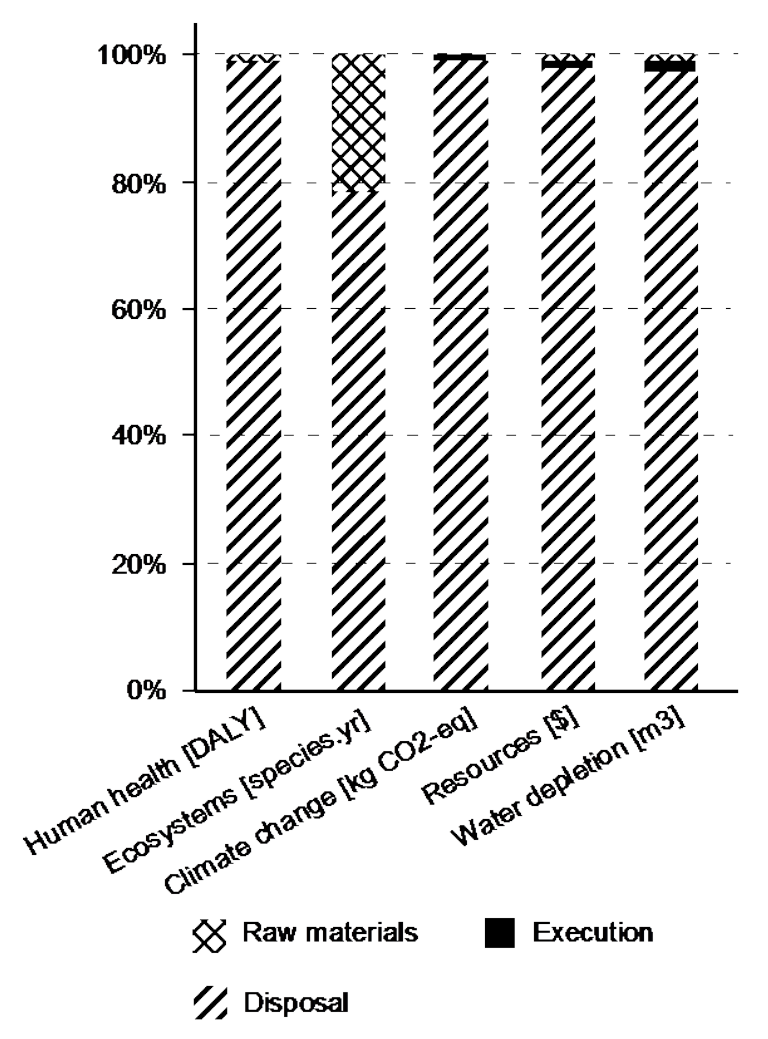

Fig. 15 Overview of the origin of the environmental impact potentials associated with sand blasting (minimum), OpenLCA 
Ohms, P., Andersen, C., Landgren, M., \& Birkved, M. (2018). Decision support for large-scale remediation strategies by fused urban metabolism and life cycle assessment. International Journal of Life Cycle Assessment (In Press). P.1-15. DOI: 10.1007/s11367-018-1445-9

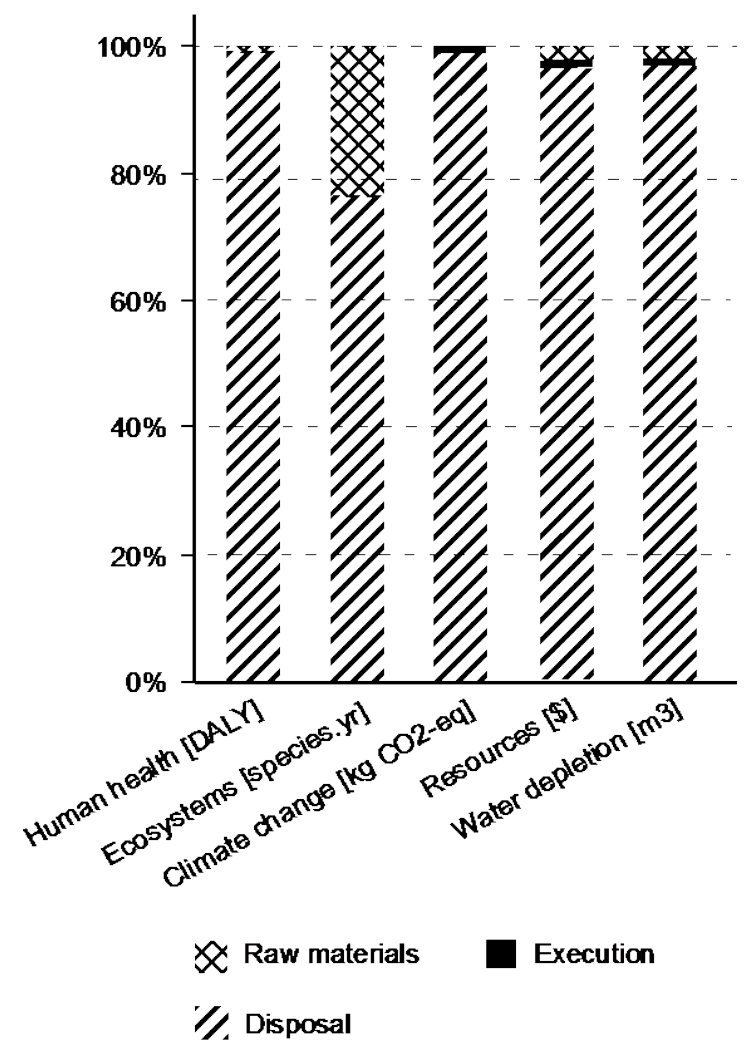

Fig. 16 Overview of the origin of the environmental impact potentials associated with steel blasting (minimum), OpenLCA 
Ohms, P., Andersen, C., Landgren, M., \& Birkved, M. (2018). Decision support for large-scale remediation strategies by fused urban metabolism and life cycle assessment. International Journal of Life Cycle Assessment (In Press). P.1-15. DOI: 10.1007/s11367-018-1445-9

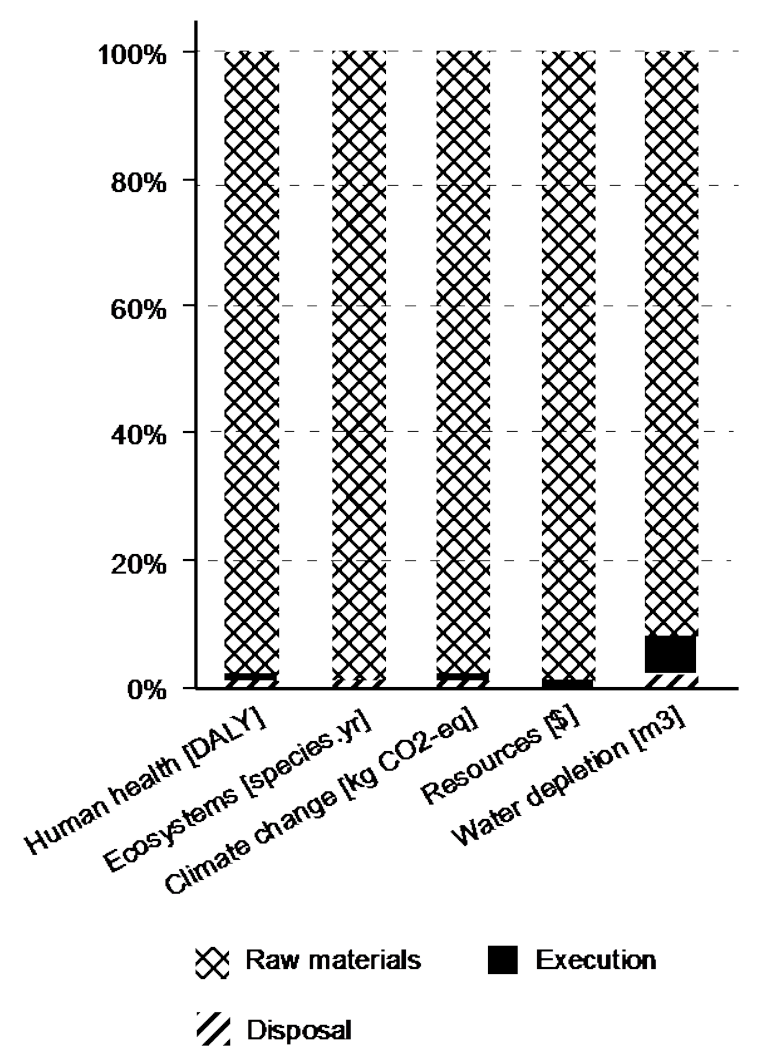

Fig. 17 Overview of the origin of the environmental impact potentials associated with surface sealing, OpenLCA 